\title{
Effect of Watsu therapy on psychological aspects and quality of life of patients with temporomandibular disorder: case report
}

\author{
Efeito da terapia Watsu sobre os aspectos psicológicos e a qualidade de vida em pacientes com disfunções \\ temporo-mandibulares: relato de caso
}

Gustavo Augusto Seabra BARBOSA'

Cibele Oliveira Melo ROCHA ${ }^{1}$

Camila Maria Bastos Machado de RESENDE

Kelly Verônica de Melo SALES

\begin{abstract}
Watsu therapy is a water relaxation intervention technique performed individually in a warm pool with music and peaceful settings involving harmonious rotational movements, stretching, tractions on the joints and pressures at the points of muscle tension. This study evaluated the effect of Watsu therapy on psychological aspects (anxiety and minor psychiatric disorders) and on the quality of life of a patient with temporomandibular disorders. The patient answered three questionnaires: STAl (State-Trait Anxiety Inventory) and GHQ (Goldberg Health Questionnaire) to assess anxiety and psychiatric disorders respectively, and WHOQOL- Brief (World Health Organization Quality of Life) to assess quality of life. Watsu therapy has been used in patients with temporomandibular disorders (TMD) such as myofascial pain diagnosed by RDC/TMD (Research Diagnostic Criteria for Temporomandibular Disorders). Psychological aspects and quality of life were assessed before and after Watsu therapy. The results after treatment showed relevant and significant improvement on all indices evaluated. Therefore, it was shown that Watsu therapy was effective in reducing anxiety and minor psychiatric disorders, as well as improved quality of life of patients with temporomandibular disorder.
\end{abstract}

Indexing terms: Anxiety disorders. Quality of life. Temporomandibular joint disorder. Temporomandibular joint disorder syndrome.

\section{RESUMO}

A terapia Watsu é uma técnica de terapia aquática para relaxamento realizada individualmente em piscina aquecida com música em ambiente tranquilo e harmonioso, envolvendo movimentos rotacionais, alongamento, trações nas articulações e pressões em pontos de tensão muscular Este estudo avaliou o efeito da terapia Watsu nos aspectos psicológicos (ansiedade e distúrbios psiquiátricos menores) e a qualidade de vida de uma paciente com disfunção temporo-mandibular. A paciente respondeu a três questionários: Inventário de Ansiedade - Resumido - Estado e Questionário de Saúde Geral para avaliar ansiedade e distúrbios psiquiátricos menores, respectivamente e; o Questionário de Qualidade de Vida da Organização Mundial de Saúde. A terapia Watsu foi usada em paciente com disfunção temporo-mandibular, como dor miofascial diagnosticada pelos Critérios de diagnóstico em pesquisa para Disfunção Temporo-mandibular. Os aspectos psicológicos e qualidade de vida foram avaliados antes e após a terapia Watsu. Os resultados após o tratamento mostraram melhora relevante e significativa em todos os índices avaliados. Portanto, pode-se concluir que a terapia Watsu foi eficaz na redução de ansiedade e distúrbios psiquiátricos menores, bem como melhora da qualidade de vida em paciente com disfunção temporo-mandibular.

Termos de indexação: Transtornos de ansiedade. Qualidade de vida. Transtornos da articulação temporo-mandibular. Síndrome da disfunção da articulação temporo-mandibular.

\section{INTRODUCTION}

Temporomandibular disorders comprise several functional disorders of masticatory structures and temporomandibular joints ${ }^{1-2}$. Its etiology is multifactorial', usually caused by unfavorable interaction of neuromuscular, joint, occlusal and psychological ${ }^{3}$ factors. The psychological aspect was reported by a study ${ }^{4}$ in which patients diagnosed with myofascial pain and other joint conditions (arthralgia and osteoarthritis) showed highly significant levels of depression and somatization. Levels of anxiety significantly high have been observed in patients with $\mathrm{TMD}^{5}$. The association of stress, anxiety, tension and dysfunction of skeletal muscles has been extensively reported ${ }^{6-8}$; however, the mechanisms that connect these factors weren't described ${ }^{9}$.

For TMD patients, a conservative, noninvasive therapy must be indicated. This therapy is a multidisciplinary medical model similar to those applied to other musculoskeletal disorders that involve the patient's physical and behavioral habits regarding their individual problem. It was observed

\footnotetext{
${ }^{1}$ Universidade Federal do Rio Grande do Norte, Departamento de Odontologia, Centro Integrado de Atendimento a portadores de Disfunção do Aparelho Estomatognático. Av. Salgado Filho, 1787, Lagoa Nova, 59056-000, Natal, RN, Brasil. Correspondência para / Correspondence to: GAS BARBOSA. E-mail: <seabrabarbosa@uol.com.br>
} 
that most of the patients with TMD experienced good symptom relief with noninvasive and reversible therapy ${ }^{10}$. Thus, intervention in TMD should be based on the integration of physical and psychological processes ${ }^{10}$.

Several types of treatment, alone or combined, have been proposed for patients with TMD specifically aimed at reducing pain ${ }^{11}$ such as physiotherapy ${ }^{10,12-13}$.

Watsu therapy is an aquatic relaxation technique created by Harolld Dull in California. It is performed individually in a warm pool with music and peaceful settings, and includes harmonious rotational movements, stretching, tractions on the joints and pressures on muscle tension points. The water support and rhythmic continuous movements flowing from one position to another allow the practitioner to experience a floating sensation. This happens due to the anti-gravitational characteristic of water and the support given by the therapist with gentle movements. This therapy is indicated in cases of muscle tension, pain, anxiety, depression, stress and sleep disorders ${ }^{14}$.

This study aims at assessing psychological aspects (anxiety and minor psychiatric disorders) and the quality of life of patients with temporomandibular disorders who were submitted to Watsu therapy.

\section{CASE REPORT}

\section{Evaluation of temporomandibular disorders}

Patient MOBS, female, 62 years old, sought for assistance at the Orofacial Pain Service at Federal University of Rio Grande do Norte, complaining of pain and fatigue in the area around the ear and no general body pain or fibromyalgia diagnoses. The patient also reported a high level of stress related to her daily activities and fatigue in an area of her face for more than a year as she wakes up, which is an indication of chronic pain. After clinical examination, it was observed pain to palpation of the masseter and anterior temporal and the presence of dental wear that associated to the patient's report indicated a possible nocturnal parafunctional habit.

In order to evaluate the presence and the characteristics of TMD, in addition to clinical examination, she answered an RDC/TMD questionnaire. This questionnaire is a valid and reproducible instrument used worldwide for TMD diagnosis. After the application of RDC/TMD questionnaire, it was verified that the patient sustained temporomandibular disorders and associated myofascial pain.

\section{Evaluation of psychological aspects and quality of life}

Goldberg health questionnaire (GHQ) and StateTrait Anxiety Inventory (STAI) were used in the psychological evaluation.

Application of Goldberg's General health questionnaire (GHQ) aims at evaluating five factors of psychiatric condition and a general score of mental disorders, providing a psychiatric profile of minor disturbances of the subject. The profile is expressed in six factors: mental stress, death wish, distrust of performance, sleep disturbances, psychosomatic disorders and general health. GHQ is comprised of 60 items regarding nonpsychotic psychiatric symptoms, and recommended for people aged 19 onwards. The 60 items can be distributed into factors, each one covering a different concept that jointly result in a general construct for mental health.

State-Trait Anxiety Inventory (STAl) was set to provide a brief self-report scale to assess anxiety in clinical practice and research. Its application is indicated for normal adults as a way to measure anxiety objectively, represented by two components: anxiety state (A-State) and anxiety trait (A-Trait). STAI consists of 20 statements in which the patient indicates feelings at a determined moment in time (A-State). The anxiety trait questionnaire is also composed of 20 items, but on this scale the patients answer about their feelings throughout their lifetime.

The quality of life assessment used in this study was WHOQOL-Brief (World Health Organization Quality of Life) derived from data collected from a fill-out questionnaire (WHOQOL-100). It generates scores for four domains related to quality of life (physical, psychological, social relationship and environmental health), and it can be used by health professionals in monitoring and evaluating the effectiveness of different treatments.

\section{Therapy}

Watsu is a delicate technique, but it exerts a deep effect and has large therapeutic potential. Bodywork is mainly performed in water at $35^{\circ} \mathrm{C}$ where the instructor leads the receiver to stretching; provides therapeutic manipulations; and guides rhythmic movements; sometimes freely, sometimes sequential, but the patient is always floating on his arms.

The technique is carried out in a warm pool with illumination and music carefully planned to offer a moment of relaxation and comfort. The purpose is to provide body freedom that is only possible in aquatic environment, relieving muscle and psychic tension. 
In the current study 10 sessions were conducted, one session per week of 40 to 60 minutes each. The movements performed in these sessions were: breathing dance, breathing balance, spine release, arm-rotating spiral, inside leg rotation, outside leg rotation, spine lengthening, arm/forearm pressure, hand on the heart master point, arm pulling, free quiet flying with the arm on the front, and massaging (trapezius, scalene, face and scalp). All movements were performed bilaterally.

After therapy application, all the assessed features were analyzed again. The patient signed a consent term.

\section{RESULTS}

The results obtained in the state trait anxiety inventory were extremely different in the pre- and posttreatment for A-State (50 to 32) and A-Trait (64 to 34). However, it was noticed that with the decrease of A-Trait, there was a consistent decrease of A-State levels (Table 1).

Table 1. STAl scores before and after treatment for trait and state anxiety.

\begin{tabular}{lcc}
\hline STAl & Before treatment & After treatment \\
\hline Trait anxiety & 64 & 34 \\
State anxiety & 50 & 32 \\
\hline
\end{tabular}

Just the same, the initial results of the General Health Questionnaire of Goldberg indicated a disturbance in values above the recommended level in all dimensions of the original studies for Psychological Stress (2.91); Death Wish (2.36), Distrust in Performance (2.95), Sleep Disorders (3.30), Psychosomatic Disorders (3.38); and consequently, General Health (2.88). The second time the patient filled - out the forms, there was a significant decrease of score values in the same dimensions, and the values were at normal levels (Table 2).

Table 2. General Health Questionnaire (GHQ) before and after treatment divided in five factors of psychiatric character and a general score of mental disorders.

\begin{tabular}{lcc}
\hline GHQ & Before treatment & After treatment \\
\hline Dying wish & 2.36 & 1.27 \\
Mental stress & 2.91 & 1.30 \\
Distrust in performance & 2.95 & 1.25 \\
Sleep disturbance & 3.30 & 1.20 \\
Psychosomatic disorders & 3.38 & 1.38 \\
General health & 2.88 & 1.30 \\
\hline
\end{tabular}

The results of quality of life indicators measured by WHOQOL-Brief showed the same important variations in the score patterns of the tests described previously for preand post-treatment. Therefore, in pre- and post-treatment respectively, the results verified in the four domains were 11 to 15 in Physical; 12 to 14 in Psychological; 12 to 12 in Social; and 11 to 14 in Environmental. These indicators reflect an improvement in the quality of life of the patient with a decrease in the levels of situational anxiety. Moreover, the scores show that healthier levels of adaptive aspects (performance, sleep, physiological self-perception, as well as physical and environmental factors) could be reestablished (Table 3).

Table 3. Results of quality of life evaluated by WHOQOL-Brief, before and after treatment divided in four domains.

\begin{tabular}{lcc}
\hline WHOQOL-Brief & Before treatment & After treatment \\
\hline Physical domain & 11 & 15 \\
Psychological domain & 12 & 14 \\
Social domain & 12 & 12 \\
Environmental domain & 11 & 14 \\
\hline
\end{tabular}

\section{DISCUSSION}

TMD is a functional disorder of the stomatognathic system, including conditions that affect the masticatory muscles and/or the temporomandibular joints ${ }^{1-2}$. Its etiology is multifactorial ${ }^{1}$ with a multifactorial combination of physical and psychosocial aspects ${ }^{6-9}$. Some studies suggest that stress and anxiety have a peripheral effect via the sympathetic nervous system which exacerbates the interaction of painful substances between the nociceptive primary afferent nerve terminals and the circulatory system. Furthermore, it is suggested that the central processing of nociceptive information and the resulting reflex activity can be boosted by anxiety and stress, which increases the perception of pain or pain response ${ }^{9}$.

There are vulnerable individuals who are predisposed to abnormalities of hormonal responses to stress which may lead to the development of a wide range of conditions such as depression and chronic facial pain ${ }^{15}$. TMD is well tolerated by most people except for a significant minority that shows a dysfunctional behavior of chronic pain associated to psychological disorders, such as depression and somatization ${ }^{16}$. After a stressful event, inappropriate responses of adaptation of the individual can act as a stressor agent for itself (the pain itself may be a 
strong stressor agent) feeding a vicious cycle ${ }^{17}$, i.e., chronic pain that could be exacerbated by psychological changes would make the individual condition worse. Therefore, it can be explained by a multidisciplinary approach to patients with chronic TMD that includes relaxation therapies and/or behavioral changes in an attempt to prevent the increase of pain experience of patients due to psychological conditions. Notwithstanding, relaxation therapy can help the patient to control their pain, breaking this vicious cycle.

In regard to TMD subgroups, the comparison of patients with muscle pain to those with joint pain shows a tendency of patients with muscle pain to develop more psychological problems, worse sleep quality and larger quantities of stressor agents ${ }^{6-7}$. In the present study, after the application of the RDC/TMD, the patient was diagnosed with myofascial pain and in some way more susceptible to psychological problems as shown in this study.

A multidisciplinary medical model, similar to those used for other musculoskeletal disorders involving the patient physical and behavioral conduct of his own problem, was proposed based on the observation that the majority of TMD patients get good relief of symptoms with reversible non-invasive therapy ${ }^{10}$. For many healthcare professionals, the subjectivity of pain experience is often overlooked even when the clinician does not find a plausible biological explanation for the pain ${ }^{17}$. The conduct of TMD should be based on integration between physical and psychological processes, i.e., stressors such as depression, anxiety, sleep disorders and others ${ }^{8}$ should also be treated by preventing the progression of an acute condition to chronic pain and promote pain relief ${ }^{11}$. Physical therapy was reported as a useful therapy, reversible and non-invasive for patients with $T D^{10}, 12-13,18$. There is some evidence that the following procedures can be effective in alleviating TMD pain: behavioral therapy, jaw exercises and postural training ${ }^{19}$. Some techniques and resources need more studies to prove its effectiveness in the treatment of TMD20.

Gusi et al. ${ }^{21}$ evaluated short-term and long-term effectiveness of exercise therapy in a heated swimming pool in women with fibromyalgia. They observed that the quality of life was improved in $93 \%$ and pain was

\section{REFERENCES}

1. Barbosa GAS, Badaró Filho CR, Fonseca RB, Soares CJ, Neves FD, Fernandes Neto AJ. The role of occlusion and occlusal adjustment on temporomandibular dysfunction. Braz J Oral Sci. 2004;3(11):589-94 reduced by $29 \%$ compared to the control during training and even after the therapy interruption. In the present study, it was observed a significant decrease in anxiety levels, as well as a substantial improvement in the quality of life of the patient, when Watsu therapy was used. Therapies that involve relaxation provide superior capability to control pain, whereas physical therapy (humid heat, cold application and massage techniques) promotes only pain relief ${ }^{12}$.

Another important factor to evaluate the impact of a disease and the effectiveness of treatments is quality of life. Individuals can change their standards and/or internal values as a result of external factors such as treatment or change in their health status. In this study, it was observed a great improvement in the quality of life of the patient after treatment, remaining steady only in the social field. Moreover, the results indicate that the benefits of Watsu therapy, such as relaxation, were probably responsible for the improvement of the patient's quality of life, physical, psychological and environmental domains. This therapy is not directly aimed at the signs and symptoms of TMD, but at its psychosocial aspects.

\section{CONCLUSION}

Based on these results and within the limitations of this study, it can be concluded that Watsu therapy was effective in reducing anxiety and minor psychiatric disorders, as well as quality of life improvement of a patient with temporomandibular disorders, such as myofascial pain. Studies should be conducted to verify the effect of this therapy in a larger number of individuals.

\section{Collaborators}

GAS BARBOSA has supervised attendance, written and reviewed the final paper. COM ROCHA has provided odontological attendance and written the paper. CMBM RESENDE carried out bibliographic research, wrote and corrected the paper. KVM SALES provided physical therapy attendance and wrote the paper.

2. Okeson JP. Occlusion and functional disorders of the masticatory system. Dent Clin North Am. 1995;39(2):285-300.

3. Clark GT, Green EM, Dornan MR, Flack VF. Craniocervical dysfunction levels in a patient sample from a temporomandibular joint clinic. J Am Dent Assoc. 1987;115(2):251-6.

4. Yap AUJ, Tan KBC, Chua EK, Tan HH. Depression and somatization 
in patients with temporomandibular disorders. J Prosth Dent. 2002;88(5):479-84. doi: 10.1067/mpr.2002.129375.

5. Southwell J, Deary IJ, Geissler P. Personality and anxiety in temporomandibular joint syndrome patients. J Oral Rehabil. 1990;17(3):239-43.

6. Bertoli $E$, de Leeuw R, Schmidt JE, Okeson JP, Carlson CR. Prevalence and impact of post-traumatic stress disorder symptoms in patients with masticatory muscle or temporomandibular joint pain: differences and similarities. J Orofac Pain. 2007;21(2):107-19.

7. Bonjardim LR, Gavião MB, Pereira LJ, Castelo PM. Anxiety and depression in adolescents and their relationship with signs and symptoms of temporomandibular disorders. Int J Prosthodont. 2005;18(4):347-52

8. Suvinen $\mathrm{TI}$, Reade PC, Kemppainen P, Könönen M, Dworkin SF. Review of aetiological concepts of temporomandibular pain disorders: towards a biopsychosocial model for integration of physical disorder factors with psychological and psychosocial illness impact factors. Eur J Pain. 2005;9(6):613-33. doi: 10.1016/j.ejpain.2005.01.012.

9. Dworkin SF. et al Epidemiology of signs and symptoms of temporomandibular disorders: clinical signs in case and controls. J Amer Dent Assoc. 1990;120(3):273-81.

10. McNeill C. Management of temporomandibular disorders: concepts and controversies. J Prosthet Dent. 1997;77(5):51022. doi: 10.1016/S0022-3913(97)70145-8.

11. Al-Ani Z, Gray R. TMD current concepts: 2 . Imaging and treatment options: an update. Dent Update. 2007;34(6):356-70.

12. Riley JL 3rd, Myers CD, Currie TP, Mayoral O, Harris $R G$, Fisher JA, et al. Self-care behaviors associated with myofascial temporomandibular disorder pain. J Orofac Pain. 2007;21(3):194-202.

13. Rocabado M, Johnston BE Jr, Blakney MG. Physical therapy in dentistry: an overview. J Craniomandibular Pract. 1982;1(1):46-9.
14. Dull H. Watsu: exercícios para o corpo na água. São Paulo: Summus Editorial; 2001.

15. Korszun A. Facial pain, depression and stress - connections and directions. J Oral Pathol Med. 2002; 31(10):615-9. doi: 10.1034/j.1600-0714.2002.00091.x.

16. Dworkin SF, Massoth DL. Temporomandibular disorders and chronic pain: disease or illness? J Prosthet Dent. 1994;72(1):2938. doi: 10.1016/0022-3913(94)90213-5.

17. Gameiro GH, Gameiro PH, Andrade AS, Pereira LF, Arthuri MT, Marcondes FK, et al. Nociception- and anxiety-like behavior in rats submitted to different periods of restraintstress. Physiol Behav. 2006;87(4):643-9. doi: 10.1016/j.physbeh.2005.12.007.

18. La Touche R, Fernández-de-las-Peñas C, Fernández-Carnero J, Escalante K, Angulo-Díaz-Parreño S, Paris-Alemany A, et al. The effects of manual therapy and exercise directed at the cervical spine on pain and pressure pain sensitivity in patients with myofascial temporomandibular disorders. J Oral Rehabil. 2009;36(9):644-52. doi: 10.1111/j.1365-2842.2009.01980.x.

19. List T, Axelsson S. Management of TMD: evidence from systematic reviews and meta-analyses. J Oral Rehabil. 2010;37(6):430-51. doi: 10.1111/j.1365-2842.2010.02089.x.

20. Oliveira KA, Pinheiro COA, Freitas DG, Gualberto HD, Carvalho NAA. A abordagem fisioterapêutica na disfunção da articulação temporomandibular: revisão da literatura. Med Reabil. 2010;29(3):61-4.

21. Gusi N, Tomas-Carus P, Häkkinen A, Häkkinen K, OrtegaAlonso $A$. Exercise in waist-high warm water decreases pain and improves health-related quality of life and strength in the lower extremities in women with fibromyalgia. Arthritis Rheum. 2006;55(1):66-73. doi: 10.1002/art.21718.

Received on: 3/1/2012 Final version resubmitted on: 5/5/2013 Approved on: 3/8/2013 
